\title{
COMBINED STERNAL BIOPSY AND ASPIRATION NEEDLE
}

\author{
BY

\section{B. A. THOMPSON}

From the Group 9 Pathological Laboratory, Peace Memorial Hospital, Watford

(RECEIVED FOR PUBLICATION OCTOBER 18, 1951)

In the August issue of this journal Bernstock and Sterndale (1951) described a combined sternal biopsy and aspiration needle, using as a basis a Sahlah type marrow needle. Before publication of this device we had made a similar type of needle, using as a basis a Waterfield (1946) sternal needle. From experience we have found that the Waterfield pattern gives greater control while performing the puncture; the screw thread type guard is more easily adjusted and gives a greater degree of safety over the slip type guard of the Sahlah pattern.

As shown in the photographs, the principle of the combined needle is the same as that of Bernstock and Sterndale, namely an outer needle of the Waterfield pattern with a bore of 14 British wire gauge, and an inner needle consisting of a trephine with a bore of 17 British wire gauge. The upper ends of both the outer and inner needles have a Record syringe fitting.

We should like to thank Messrs. S. J. Owen, of 35 Northampton Square, London, E.C.1, for making both inner and outer needles ; and Dr. E. Elkan for the photographs.

\section{REFERENCES}

Bernstock, L., and Sterndale, H. (1951). Journal of Clinical Pathology, 4, 378.

Waterfield, R. L. (1946). Lancet, 1, 576.

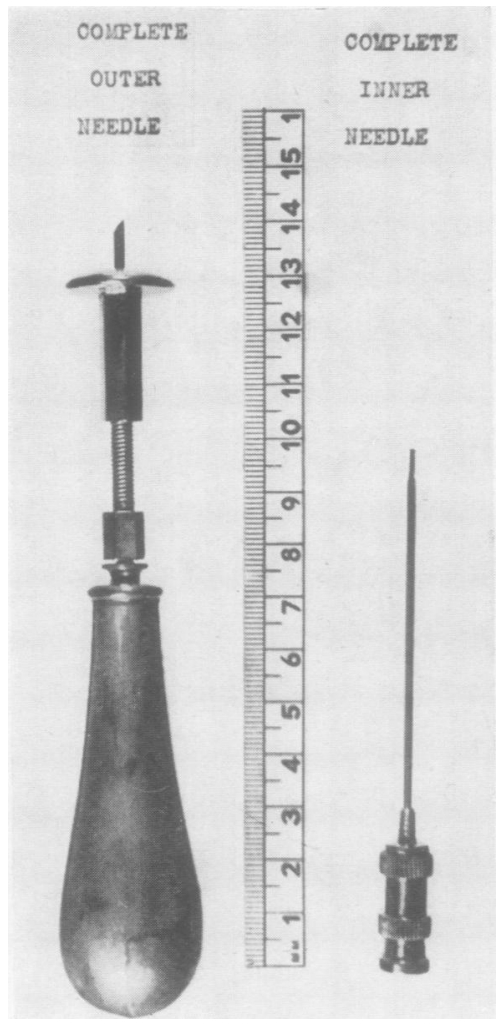

FIG. 1

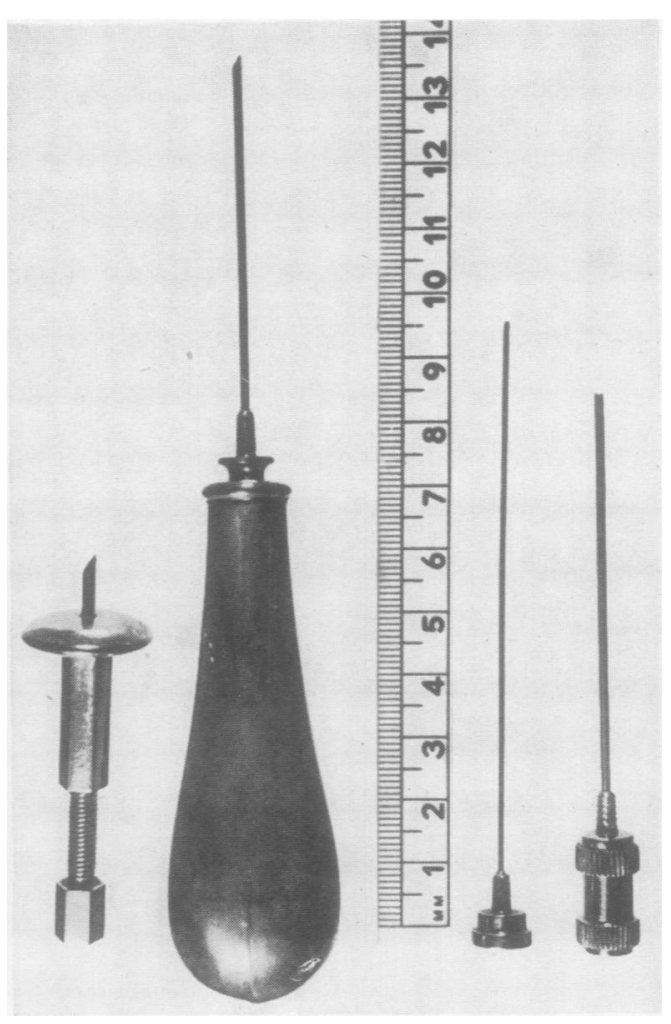

FIG. 2
FIG. 1-Outer needle and trephine with stylet in_situ.

FIG. 2-Both needles dismounted showing component parts. 